\title{
PRODUTIVIDADE DE AMENDOIM EM FUNÇÃO DA CALAGEM E DO MÉTODO DE SECAGEM ${ }^{1}$
}

\author{
ELENA MERCEDES FERNANDES ${ }^{2}$ e CIRO ANTONIO ROSOLEM ${ }^{3}$
}

\begin{abstract}
RESUMO - Estudar o efeito da calagem e do método de secagem na produtividade do amendoim (Arachis hypogea L., cv. Botutatu) foi o objetivo deste trabalho, conduzido num solo Latossolo Vermelho-Escuro, textura média, em São Manuel, São Paulo. Os tratamentos consistiram de ausência ou presença de calagem $\left(2,05 \mathrm{Mg} \mathrm{ha}^{-1}\right)$ e secagem à sombra, ao sol e duas formas combinadas desta última com estufa. A calagem eliminou a fitotoxicidade de manganês, melhorando a nodulação e a nutrição nitrogenada, que, conseqüentemente, levaram ao aumento do número de ramificações, de vagens por planta e da produtividade. Com a calagem, observou-se também redução nas perdas durante a colheita. Das formas de secagem, a realizada à sombra e a combinada campo-estufa foram as que proporcionaram maiores produtividades, por permitirem melhor maturação dos frutos e menores perdas na colheita.
\end{abstract}

Termos para indexação: Arachis hypogaea, cálcio, nitrogênio, manganês, perdas na colheita.

\section{PEANUT YIELD AS AFFECTED BY LIMING AND DRYING METHOD}

\begin{abstract}
Peanut (Arachis hypogea L.), cv. Botutatu was grown in a Dark Red Latosol (Haplortox, sandy loam) in São Manuel, São Paulo, to study the effects of liming and drying method on grain yields. Treatments consisted of lime rates $\left(0\right.$ and $\left.2.05 \mathrm{Mg} \mathrm{ha}^{-1}\right)$ and the drying methods: shadow, field and two combinations of field + oven. Manganese toxicity desapeared in limed plots, providing a better nodulation and $\mathrm{N}$ nutrition, which in turn, led to a higher plant branching, a higher number of fruits per plant and higher yields. Yield losses were lower in limed plots. The plots dried in the shadow and in the combined field + oven method yielded more than those field dried because they allowed a better fruit maturation and lower yield losses.
\end{abstract}

Index terms: Arachis hypogea, calcium, manganese, nitrogen, yield loss.

\section{INTRODUÇÃO}

O amendoim é uma espécie que tolera acidez do solo (Adams \& Pearson, 1970), mas a baixa disponibilidade de $\mathrm{Ca}$ afeta sua produção, pela necessidade desse nutriente na zona de desenvolvimento dos frutos (Walker, 1975), que absorvem Ca da

\footnotetext{
${ }^{1}$ Aceito para publicação em 27 de abril de 1998.

Extraído da tese apresentada pelo primeiro autor à Faculdade de Ciências Agronômicas de Botucatu, UNESP.

${ }^{2}$ Enga Agra ${ }^{\mathrm{a}}$, Dra ${ }^{\mathrm{a}}$, Universidad Nacional de Río Quarto. Facultad de Agronomia y Veterinaria, Departamento de Produción Vegetal, RN 36 Km 601, 5800 Río Cuarto, Argentina.

${ }^{3}$ Eng. Agr., Dr., Prof. Titular, Dep. de Agricultura e Melhoramento Vegetal, Faculdade de Ciências Agronômicas, UNESP, Caixa Postal 237, CEP 18603-970 Botucatu, SP. E-mail: rosolem@fca.unesp.br
}

solução do solo (Sumner et al; 1988), desde o estádio R2 até R6 (Mizuno, 1959). O período crítico se estende dos 15 aos 35 dias após a entrada dos ginóforos no solo (Brady, 1947). A redução do conteúdo de água no solo diminui a absorção de $\mathrm{Ca}$, induzindo a deficiência deste na planta (Hallock \& Allison, 1980).

Em solos com deficiência de $\mathrm{Ca}$, o crescimento vegetativo e das folhas é reduzido (Rodrigues Filho et al., 1988). Caires (1990) observou, com altas doses de calcário, aumento do peso da matéria seca dos caules, mas não das folhas. A aplicação de calcário aumenta ainda o número de ginóforos (Reed $\&$ Brady, 1948), que se correlaciona com a produção (Nakagawa \& Rosolem, 1982).

Embora o crescimento radicular do amendoim seja menos afetado que o de outras espécies em 
solos ácidos (Adams \& Pearson, 1970), a elevação do $\mathrm{pH}$ ou do teor de Ca melhora o crescimento (Inoue et al., 1988) e o peso da raiz (Reddy \& Patil, 1980). Caires \& Rosolem (1991) constataram qua a aplicação de Ca melhorou a distribuição do sistema radicular, revelando resposta linear entre 18,9 e 68,1 $\mathrm{cmol}_{(+)} \mathrm{dm}^{-3}$ de Ca. O peso da matéria seca da raiz foi correlacionado positivamente com a produção (Nakagawa \& Rosolem, 1982).

O desenvolvimento dos nódulos é afetado negativamente pela acidez do solo e plantas que crescem sem calcário apresentam clorose característica de deficiência de N (Blamey \& Chapman, 1982). A calagem diminui a disponibilidade do $\mathrm{Al}$ e $\mathrm{Mn}$ no solo, evitando sua toxicidade, e aumenta a de Mo, condições químicas que favorecem a nodulação (Blamey \& Chapman, 1982).

Quando a quantidade de Ca no solo é insuficiente para cobrir as necessidades do pericarpo e da semente, ocorre aborto de óvulos (Burkhart \& Collins, 1941), observando-se frutos com menor número de sementes ou chochos (Colwell \& Brady, 1945; Cox \& Reid, 1964). Nakagawa et al. (1993) observaram aumento do número de sementes por vagem quando aplicaram calcário em solo ácido pobre em $\mathrm{Ca}$. O aumento do $\mathrm{Ca}$ no solo através da gessagem aumenta o peso das sementes maduras (Adams \& Hartzog, 1991). Entretanto, nem sempre se nota melhora da qualidade das sementes e vagens, avaliadas como chochas e podres, com a aplicação de calcário (Caires, 1990; Rossetto, 1993).

Quaggio et al. (1982) observaram que quando o nível de Ca no solo foi superior a $15,0 \mathrm{mmol}_{\mathrm{c}} \mathrm{dm}^{-3} \mathrm{ea}$ saturação por bases (V) superior a $40 \%$, não houve resposta à aplicação de calcário, enquanto Caires (1990) observou esse efeito com maiores valores de $\mathrm{Ca}\left(20,0 \mathrm{mmol}_{\mathrm{c}} \mathrm{dm}^{-3}\right)$ e de V (58\%). Em solos com baixo $\mathrm{pH}$ e $\mathrm{V}$, aumentos na produtividade em função da calagem podem ser observados (Nakagawa et al., 1993) ou não (Rossetto, 1993).

Com relação à secagem do amendoim, no Brasil os frutos ficam expostos às condições ambientais do campo até alcançarem a umidade adequada para o armazenamento, ou seja, uma redução da umidade de 30-60 para 8-10\% (Norden, 1975). Nos Estados Unidos a secagem no campo se realiza até as sementes alcançarem umidade de 15-35\% (Wright
\& Steele, 1979), seguindo-se posteriormente a secagem artificial.

Segundo Norden (1975), os grãos que ficam no campo ligados à planta podem continuar o processo de maturação. $\mathrm{O}$ incremento do tempo em que os frutos ficam no campo aumenta os riscos de perda (Norden, 1975), cuja magnitude é função da maturidade dos frutos no arrancamento, das chuvas a que são expostos no período e do conteúdo de umidade no momento do armazenamento (Young et al., 1982).

Considerando o papel do Ca na parede celular, é possível que a nutrição cálcica do amendoim tenha influência na resistência do ginóforo e na perda de água pela planta, influenciando na secagem e na porcentagem de perdas na colheita.

O objetivo deste experimento foi estudar o efeito da calagem e do método de secagem na nutrição e na produtividade do amendoim.

\section{MATERIAL E MÉTODOS}

O amendoim (Arachis hypogaea L.), cultivar Botutatu, foi cultivado na Fazenda Experimental São Manuel, da Faculdade de Ciências Agronômicas-UNESP, no município de São Manuel, SP, num Latossolo Vermelho-Escuro, textura média. Os resultados da análise química do solo (Raij, 1981) por ocasião da semeadura encontram-se na Tabela 1

O experimento foi instalado em blocos ao acaso com parcelas subdivididas, e quatro repetições. Os tratamentos foram ausência e presença de calagem e os subtratamentos foram as formas de secagem: à sombra; no campo; no campo até as sementes atingirem $24,8 \%$ de umidade; e até as sementes atingirem $35,9 \%$. A secagem das vagens dos dois últimos tratamentos foi completada em estufa a $30 \pm 1,0^{\circ} \mathrm{C}$. Todas as parcelas foram secas até $10 \%$ de umidade

O calcário dolomítico $(23,5 \%$ de $\mathrm{CaO}$ e $21,5 \%$ de $\mathrm{MgO}$ e $95 \%$ de PRNT), na dose de $2,05 \mathrm{t} \mathrm{ha}^{-1}$ (calculada para elevar a saturação por bases do solo a 70\%), foi incorporado a $20 \mathrm{~cm}$ em 22 de agosto de 1992. Na semeadura, foi realizada adubação nas linhas com $20 \mathrm{~kg} \mathrm{ha}^{-1} \mathrm{de} \mathrm{N}$, $80 \mathrm{~kg} \mathrm{ha}^{-1}$ de $\mathrm{P}_{2} \mathrm{O}_{5}$ e $40 \mathrm{~kg} \mathrm{ha}^{-1}$ de $\mathrm{K}_{2} \mathrm{O}$, nas formas de sulfato de amônio, superfosfato simples e cloreto de potássio, respectivamente. A semeadura foi realizada em 14 de outubro de 1992, no espaçamento de $60 \mathrm{~cm}$, com densidade de 20 sementes por metro linear 
Aos 32 e 51 dias após a emergência (DAE), correspondendo aos estádios R2 e R3 (Boote, 1982), foram amostradas folhas " +3 " para diagonose foliar. Após lavagem, as folhas foram secas e moídas. Os teores de $\mathrm{P}$, $\mathrm{K}, \mathrm{Ca}, \mathrm{Mg}, \mathrm{Mn}, \mathrm{Zn}$ e Fe foram obtidos por extração nitroperclórica e determinados por espectrofotometria de absorção atômica, à exceção do $\mathrm{P}$, para o qual utilizou-se espectro-colorímetro. $\mathrm{O}$ teor de $\mathrm{N}$ foi obtido por digestão sulfúrica e determinado pelo método semimicro Kjeldahl

Aos 51 DAE (R3) coletaram-se 10 plantas de cada parcela, para avaliação de altura da planta, número de nós, matéria seca da planta, área foliar e número de ginóforos.

Foi realizada irrigação e controladas as plantas daninhas, pragas e doenças. O arrancamento ocorreu aos 114 dias após a emergência. As amostras que secaram à sombra foram retiradas do campo logo após o arrancamento e colocadas para secar em galpão coberto, sobre bancadas de madeira, evitando-se contato dos frutos com o material vegetal verde e movimentadas diariamente para não apodrecerem. Nessa ocasião, foi tomada uma amostra de cinco plantas para avaliação do número e da massa nodular. As amostras que secaram no campo foram amontoadas em feixes de 25-30 plantas com os frutos para cima e também movimentadas diariamente. Antes de realizar o despencamento para levar os frutos à estufa, foram amostradas 10 plantas ao acaso, as quais foram colocadas na mesma estufa que os frutos, para avaliação dos componentes da produção.
De cada subparcela, tomaram-se 400 vagens e calculou-se a porcentagem de vagens maduras, ou seja, as que continham no mínimo uma semente totalmente desenvolvida e com tegumento vermelho

Depois de colhidas todas as plantas do campo, foram recolhidos e pesados os frutos que ficaram na superfície do terreno, calculando-se a porcentagem de perdas.

Os dados obtidos antes da colheita foram analisados estatisticamente segundo o delineamento de blocos ao acaso, com quatro repetições, e os referentes à colheita, segundo blocos ao acaso em parcelas subdivididas, com quatro repetições. Nas comparações das médias dos tratamentos adotou-se o teste de Tukey a 5 e $10 \%$ de probabilidade.

\section{RESULTADOS E DISCUSSÃO}

O peso da matéria seca das raízes (Tabela 2) aumentou quando o nível de Ca no solo passou de 5,5 para $14,6 \mathrm{cmol}_{(+)} \mathrm{dm}^{-3}$ (Tabela 1). Embora Inoue et al. (1988) não tenham observado o mesmo efeito numa faixa maior de Ca no solo (3,0 a 23,3 $\mathrm{cmol}_{(+)}$ $\mathrm{dm}^{-3}$ ), os resultados são compatíveis com os obtidos por Caires \& Rosolem (1991), que encontraram uma relação linear entre o crescimento radicular e o conteúdo de Ca no solo.

TABELA 1. Resultados da análise química do solo por ocasião da semeadura, em função da calagem.

\begin{tabular}{|c|c|c|c|c|c|c|c|c|c|}
\hline Calagem & $\mathrm{pH}^{1}$ & MO & $\mathrm{P}^{2}$ & $\mathrm{H}+\mathrm{Al}$ & $\mathrm{K}$ & $\mathrm{Ca}$ & $\mathrm{Mg}$ & CTC & V \\
\hline$\left(\mathrm{Mg} \mathrm{ha}^{-1}\right)$ & & $\left(\mathrm{g} \mathrm{kg}^{-1}\right)$ & $\left(\mathrm{mg} \mathrm{kg}^{-1}\right)$ & 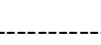 & & (mmol & & & $(\%)$ \\
\hline 0 & 4.23 & 6,3 & 3,6 & 34 & 0.7 & 5.5 & 1.8 & 42 & 19,5 \\
\hline 2,05 & 4.90 & 6,3 & 5,3 & 20 & 1.5 & 14.6 & 9.6 & 46 & 55,8 \\
\hline
\end{tabular}

${ }^{1} \mathrm{Em} \mathrm{Ca} \mathrm{Cl}_{2}$

2 Método da resina

TABELA 2. Altura da planta, número de nós por planta, peso da matéria seca de folhas, pecíolos, caule, raiz e frutos, área foliar, número de ginóforos totais e úteis (com frutos) por planta, em função da calagem, no estádio R3.

\begin{tabular}{|c|c|c|c|c|c|c|c|c|c|c|}
\hline \multirow[t]{2}{*}{ Calagem } & \multirow[t]{2}{*}{ Altura } & \multirow{2}{*}{$\begin{array}{c}\text { Número } \\
\text { de nós }\end{array}$} & \multicolumn{5}{|c|}{ Matéria seca } & \multirow{2}{*}{$\begin{array}{l}\text { Área } \\
\text { foliar }\end{array}$} & \multicolumn{2}{|c|}{ Ginóforos } \\
\hline & & & Folhas & Pecíolo & Caule & Raiz & Frutos & & Total & Úteis \\
\hline$\left(\mathrm{Mg} \mathrm{ha}^{-1}\right)$ & $(\mathrm{cm})$ & & - & 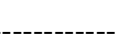 & $\left(\mathrm{g} \mathrm{pl}^{-1}\right)$ & ----- & ------ & $\left(\mathrm{cm}^{2} \mathrm{pl}^{-1}\right)$ & & \\
\hline 0 & 33,9 & 12,3 & 3,6 & 1,3 & 3,6 & 0,5 & 2,2 & 861,9 & 17,5 & 11,0 \\
\hline 2,05 & 37,9 & 13,8 & 5,6 & 2,0 & 5,9 & 0,6 & 2,8 & 1463,1 & 27,5 & 14,6 \\
\hline Média & 35,9 & 13,0 & 4,6 & 1,6 & 4,7 & 0,5 & 2,5 & 1162,5 & 22,5 & 12,8 \\
\hline $\mathrm{F}$ & $6,6^{\circ}$ & $5,3^{\mathrm{ns}}$ & $5,1^{\mathrm{ns}}$ & $8,7^{\circ}$ & $10,0^{\circ}$ & $10,2^{*}$ & $8,3^{\circ}$ & $21,8^{*}$ & $13,8^{*}$ & $2,7^{\mathrm{ns}}$ \\
\hline $\mathrm{CV}(\%)$ & 6,1 & 3,5 & 26,6 & 20,4 & 21,8 & 13,0 & 13,2 & 15,7 & 8,2 & 12,7 \\
\hline
\end{tabular}


As plantas que cresceram na presença de calcário apresentaram área foliar significativamente maior, embora o aumento de $55 \%$ na matéria seca das folhas não tenha sido estatisticamente significativo (Tabela 2). Caires (1990) observou incremento da matéria seca da parte aérea, com doses mais altas de calcário, e mais tarde no ciclo da cultura.

O número de ginóforos e a matéria seca de frutos por planta (Tabela 2) aumentaram com a aplicação de de calcário, discordando dos resultados obtidos por Caires (1990), com a mesma cultivar de amendoim, em solo classificado como Terra Roxa Estruturada. Outros parâmetros também foram modificados, embora com menor significância, tais como altura da planta, matéria seca dos pecíolos, caules e frutos (Tabela 2).

A calagem aumentou o número (de 143,6 para 236,0 ) e o peso da matéria seca (de 76,0 para $143,0 \mathrm{mg}$ ) de nódulos por planta, concordando com o observado por Blamey \& Chapman (1982). Tal comportamento pode ser devido ao aumento do $\mathrm{pH}$ e ao teor de Ca no solo (Tabela 1) no início do desenvolvimento dos nódulos, já que essa etapa é mais sensível que o crescimento posterior (Marschner, 1990). Na primeira avaliação de nutrientes nas folhas aos 32 DAE (R2), constatou-se que a calagem modificou significativamente apenas o teor de $\mathrm{N}$, que passou de 28,3 para $34,4 \mathrm{~g} \mathrm{~kg}^{-1}$. As plantas com maior teor de $\mathrm{N}$ nas folhas tinham coloração verde mais intensa, concordando com Blamey \& Chapman (1982). Os teores médios dos outros macronutrientes nas folhas foram 2,0, 15,4, 12,6 e $3,8 \mathrm{~g} \mathrm{~kg}^{-1}$ de $\mathrm{P}, \mathrm{K}$, Ca e $\mathrm{Mg}$, respectivamente. Os teores de micronutrientes foram 22,47 e $574 \mathrm{mg} \mathrm{kg}^{-1}$ de $\mathrm{Mn}, \mathrm{Zn}$ e Fe, respectivamente.Na segunda avali- ação, aos 51 DAE (R3), o calcário modificou o conteúdo de $\mathrm{P}, \mathrm{Ca}, \mathrm{Mg}$ e Mn (Tabela 3). Nessa ocasião as folhas das plantas que não receberam calcário apresentavam sintomas de toxicidade de $\mathrm{Mn}$, e necrose foliar principalmente nas margens, com aspecto de queimado. Com o decorrer do ciclo os sintomas desapareceram. O efeito depressivo da calagem nos teores de $\mathrm{P}, \mathrm{Ca}$, e $\mathrm{Mg}$ pode estar relacionado ao efeito da diluição, pois as plantas que cresceram na presença de calcário produziram 55\% a mais de matéria seca nas folhas. Os teores de $\mathrm{Ca}$ no tratamento com calcário foram inferiores aos considerados por Jones Junior et al. (1991) como adequados para o crescimento $\left(1,25-1,75 \mathrm{~g} \mathrm{~kg}^{-1}\right)$, embora o autor não especifique a cultivar. Os resultados são compatíveis aos observados por Caires (1990), em cultivares do grupo Valência e Spanish, e por Rossetto (1993) em cultivar do grupo Valência.

Os teores de $\mathrm{K}$ nas duas avaliações foram também inferiores aos considerados por Jones Junior et al. (1991) como adequados (1,70 - 3,00 $\left.\mathrm{g} \mathrm{kg}^{-1}\right)$; entretanto são comparáveis aos obtidos por Quaggio et al. (1982) e Rossetto (1993) em cultivar do grupo Valência.

Os teores de $\mathrm{P}$ e $\mathrm{Mg}$ nas folhas, por sua vez, estão dentro da faixa considerada adequada $\left(0,20-0,35\right.$ e $0,30-0,80 \mathrm{~g} \mathrm{~kg}^{-1}$, respectivamente) por Jones Junior et al. (1991), e são comparáveis aos verificados por Rossetto (1993), com a mesma cultivar deste experimento, e por Quaggio et al. (1982), com cultivar do mesmo grupo.

Os teores de $\mathrm{Fe}$ de ambos os tratamentos na primeira avaliação e no tratamento com calcário na segunda avaliação foram superiores aos valores (100 - $250 \mathrm{mg} \mathrm{kg}^{-1}$ ) propostos por Jones Junior et al.

TABELA 3. Teores de nutrientes nas folhas em função da calagem aos 51 dias (R3) após a emergência das plantas.

\begin{tabular}{|c|c|c|c|c|c|c|c|c|}
\hline Calagem & $\mathrm{N}$ & $\mathrm{P}$ & $\mathrm{K}$ & $\mathrm{Ca}$ & $\mathrm{Mg}$ & $\mathrm{Mn}$ & $\mathrm{Zn}$ & $\mathrm{Fe}$ \\
\hline$\left(\mathrm{Mg} \mathrm{ha}^{-1}\right)$ & 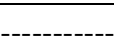 & - & $\mathrm{g} \mathrm{kg}^{-1}$ & - & ----- & - & $-(\mathrm{mg} \mathrm{kg}$ & - \\
\hline 0 & 2,98 & 0,18 & 1,26 & 1,28 & 0,38 & 225,5 & 46,0 & 223,5 \\
\hline 2,05 & 3,18 & 0,16 & 1,25 & 1,11 & 0,34 & 164,0 & 34,5 & 264,5 \\
\hline Média & 3,08 & 0,17 & 1,25 & 1,20 & 0,36 & 194,8 & 40,3 & 244,0 \\
\hline $\mathrm{F}$ & $4,6^{\mathrm{ns}}$ & $11,9^{*}$ & $0,4^{\mathrm{ns}}$ & $94,7^{*}$ & $74,8^{* *}$ & $278,5^{* *}$ & $1,6^{\mathrm{ns}}$ & $3,1^{\mathrm{ns}}$ \\
\hline $\mathrm{CV}(\%)$ & 2,3 & 2,8 & 1,1 & 1,0 & 1,1 & 2,7 & 28,8 & 13,5 \\
\hline
\end{tabular}


(1991), como adequados ao crescimento. Os teores de $\mathrm{Zn}$ estiveram dentro da faixa considerada adequada (20 - 50 ppm) e os de Mn, diminuídos pela calagem, foram inferiores a $687 \mathrm{mg} \mathrm{kg}^{-1}$, considerado tóxico (Bekker et al., 1994), ou $1.245 \mathrm{mg} \mathrm{kg}^{-1}$, depressor do crescimento segundo Morris \& Pierre (1949). Entretanto, os valores aqui observados foram suficientes para produzir sintomas de fitotoxicidade. Outros autores já observaram o efeito depressivo da calagem na quantidade de Mn nas folhas (Quaggio et al., 1982). Em soja, Heenan \& Carter (1977) relataram que a fitotoxicidade de $\mathrm{Mn}$ se manifesta em períodos de temperaturas baixas, 0 que deve ter ocorrido no presente trabalho, visto que em final de novembro verificou-se tal situação climática. Com a elevação da temperatura os sintomas desapareceram.

Por ocasião da colheita a aplicação de calcário aumentou o número de ramificações $n+2$ e totais por planta (Tabela 4); fato que pode ter sido causado pela melhor nutrição nitrogenada. Esse parâmetro não foi modificado pelo método de secagem.

As plantas retiradas do campo logo após o arrancamento tinham mais ramificações primárias $(4,3)$ que aquelas que permaneceram no campo $(3,9)$, em virtude da movimentação a que foram submetidas para favorecer a secagem.

O número de ginóforos úteis (Tabela 4) foi aumentado pela aplicação de calcário, concordando com Reed \& Brady (1948). O Ca é um dos fatores que influencia o crescimento dessas estruturas, já que interfere na divisão e no alongamento celular (Burström, 1968). Como esse elemento é absorvido pelas raízes e movimenta-se seguindo o fluxo transpiratório (Kvien et al., 1988), a absorção foi favorecida pela maior superfície evaporante (maior área foliar) no tratamento com calcário (Tabela 2).
Embora os teores de Ca nas folhas tenham sido menores na presença de calagem, a quantidade absorvida provavelmente foi maior, em função da maior produção de matéria seca.

O número de vagens foi aumentado pela aplicação de calcário (Tabela 5). Esse incremento em parte, deve-se ao aumento das ramificações (Tabela 4).

O Ca não teve efeito no aumento da resistência dos ginóforos, no momento da colheita (Tabela 5), uma vez que o número de vagens caídas foi o mesmo com e sem calagem. O incremento do tempo de secagem, todavia, favoreceu a perda de vagens, pela movimentação das plantas.

A calagem favoreceu a maturação (Tabela 5), concordando com Blamey \& Chapman (1982). A maior disponibilidade de $\mathrm{Ca}$ pode ter concentrado a frutificação, uniformizando-a e, conseqüentemente, aumentando a porcentagem de frutos maduros na colheita. Essa característica favorece a secagem e o armazenamento, já que frutos verdes têm maior quantidade de água que os maduros. A secagem no campo aumentou a porcentagem de vagens maduras quando comparadas com as deixadas à sombra. Esses dados concordam com Norden (1975), que observou que os frutos ligados à planta durante a secagem no campo continuam o processo de maturação.

O número de sementes por vagem foi modificado pelos tratamentos aplicados (Tabela 5). A calagem aumentou o número de vagens com uma, três e quatro sementes. Nakagawa et al. (1993) observaram, quando aplicaram calcário num solo com semelhantes condições às deste experimento, aumento do número de sementes por vagens. O número é determinado no momento da fertilização, quando a disponibilidade de Ca é de real importância, já que o nutriente intervém no crescimento e na direção do tubo polínico (Mascarenhas \& Machkis, 1964).

TABELA 4. Número de ramificações da haste principal $(n+1$ e $n+2)$ e totais, ginóforos úteis e totais por planta no momento da colheita em função da calagem.

\begin{tabular}{cccccc}
\hline \multirow{2}{*}{$\begin{array}{c}\text { Calagem } \\
\left(\mathrm{Mg} \mathrm{ha}^{-1}\right)\end{array}$} & \multicolumn{2}{c}{ Ramificações } & \multicolumn{2}{c}{ Ginóforos } \\
\cline { 2 - 6 } & $\mathrm{n}+1$ & $\mathrm{n}+2$ & Totais & Úteis & Totais \\
\hline 0 & 4,1 & 0,4 & 4,5 & 23,8 & 51,0 \\
2,05 & 4,2 & 1,0 & 5,3 & 33,2 & 53,2 \\
$\mathrm{~F}$ & $1,1^{\mathrm{ns}}$ & $9,7^{*}$ & $9,3^{\mathrm{o}}$ & $5,9^{\mathrm{o}}$ & $1,2^{\text {ns }}$ \\
\hline $\mathrm{CV}(\%)$ & 8,4 & 22,6 & 15,3 & 38,4 & 10,9 \\
\hline${ }^{\circ}, *$ Teste $\mathrm{F}$ significativo nos nivveis de 10 e $5 \%$ de probabilidade, respectivamente.
\end{tabular}


TABELA 5. Número de vagens na planta e caídas, porcentagem de vagens maduras e número de vagens por planta com uma, duas, três, quatro e cinco sementes, em função da calagem e do método de secagem ${ }^{1}$.

\begin{tabular}{|c|c|c|c|c|c|c|c|c|}
\hline \multirow[t]{2}{*}{ Calagem } & \multicolumn{3}{|c|}{ Vagens } & \multicolumn{5}{|c|}{ Vagens com } \\
\hline & Na planta & Caídas & Maduras & Uma sem. & Duas sem. & Três sem. & Quatro sem. & Cinco sem. \\
\hline$\left(\mathrm{Mg} \mathrm{ha}^{-1}\right)$ & \multicolumn{2}{|c|}{$\left(\mathrm{n}^{\circ} \mathrm{pl}^{-1}\right)$} & $(\%)$ & \multicolumn{5}{|c|}{$\left(\mathrm{n}^{\circ} \mathrm{pl}^{-1}\right)$} \\
\hline 0 & 9,2 & 2,8 & 97,0 & 0,7 & 2,2 & 4,0 & 2,0 & 0,02 \\
\hline 2,05 & 14,4 & 2,9 & 98,9 & 1,4 & 3,3 & 6,3 & 3,4 & 0,02 \\
\hline $\mathrm{F}$ & $7,9^{\circ}$ & $0,0^{\mathrm{ns}}$ & $33,7^{*}$ & $33,2^{*}$ & $3,2^{\mathrm{ns}}$ & $7,4^{\circ}$ & $51,0^{* *}$ & $0,0^{\mathrm{ns}}$ \\
\hline $\mathrm{CV}(\%)$ & 39,6 & 35,3 & 1,0 & 34,2 & 64,4 & 46,0 & 19,9 & 2,7 \\
\hline \multicolumn{9}{|l|}{ Secagem $^{2}$} \\
\hline Sombra & $12,1 \mathrm{a}$ & $2,6 a b$ & $97,4 b$ & $0,9 a$ & $3,1 \mathrm{a}$ & $5,3 \mathrm{ab}$ & $3,0 \mathrm{a}$ & $0,00 \mathrm{a}$ \\
\hline Campo & $10,7 \mathrm{a}$ & $4,1 \mathrm{a}$ & $98,5 \mathrm{a}$ & $0,9 a$ & $2,3 \mathrm{a}$ & $4,5 b$ & $2,3 \mathrm{a}$ & $0,02 \mathrm{a}$ \\
\hline Estufa 1 & $12,1 \mathrm{a}$ & $3,0 \mathrm{ab}$ & $97,6 a b$ & $1,2 \mathrm{a}$ & $2,9 a$ & $4,9 \mathrm{ab}$ & $2,5 \mathrm{a}$ & $0,02 \mathrm{a}$ \\
\hline Estufa 2 & $12,3 \mathrm{a}$ & $1,8 b$ & $98,0 \mathrm{ab}$ & $1,1 \mathrm{a}$ & $2,8 \mathrm{a}$ & $5,8 \mathrm{a}$ & $3,0 \mathrm{a}$ & $0,00 \mathrm{a}$ \\
\hline Média & 11,8 & 2,9 & 97,9 & 1,0 & 2,8 & & 2,7 & 0,02 \\
\hline $\mathrm{F}$ & $0,9^{\circ}$ & $45,8^{*}$ & $4,4^{*}$ & $0,9^{\text {ns }}$ & $2,0^{\mathrm{ns}}$ & $3,0^{*}$ & $2,7^{\circ}$ & $1,5^{\mathrm{ns}}$ \\
\hline $\mathrm{CV}(\%)$ & 17,9 & 43,3 & 0,7 & 45,7 & 41,3 & 16,8 & 22,6 & 3,1 \\
\hline
\end{tabular}

${ }^{1}$ Médias seguidas da mesma letra na coluna não diferem estatisticamente pelo teste de Tukey a $5 \%$ de probabilidade

${ }^{2}$ Estufa 1: campo até $24,8 \%$ e depois estufa; Estufa 2: campo até $35,9 \%$ e depois estufa.

$\circ, *, * *$ Teste $\mathrm{F}$ significativo a 10,5 e $1 \%$ de probabilidade, respectivamente.

O modo de secagem teve efeito no número de vagens com três e quatro sementes. $\mathrm{O}$ incremento do tempo de secagem em função do método utilizado diminuiu o número desse tipo de vagem, uma vez que a perda de ramificações $n+1$ (Tabela 4 ), nas quais acham-se os frutos mais maduros e provavelmente os de três sementes, representam $44 \%$ do total de vagens.

A calagem causou aumento no peso das sementes e das cascas por planta (Tabela 6), possivelmente em razão do aumento do número de vagens (Tabela 5). Além disso, o peso das sementes também relacionou-se ao incremento do número de vagens de três sementes (Tabela 5), pela alta porcentagem que essas representam. Adams \& Hartzog (1991), trabalhando com gesso, observaram aumento do peso das sementes e o atribuíram à maior disponibilidade de Ca no solo.

O peso das sementes imaturas por planta não foi modificado pela calagem nem pelo sistema de secagem.

A qualidade de vagens e sementes foi avaliada visualmente (Tabela 7). A calagem não teve efeito nos parâmetros avaliados, concordando com Caires (1990) e Rossetto (1993). O sistema de secagem influenciou a sanidade das vagens, embora as diferenças sejam mínimas. As que secaram ao sol apresentavam-se mais deterioradas, pois ficaram sujeitas às flutuações de umidade ou sob alta umidade relativa, que impediu a secagem rápida e favoreceu o crescimento do fungo.

As perdas na colheita foram influenciadas pela calagem e pelo método de secagem (Tabela 8). As plantas que ficaram no campo por mais tempo tiveram as maiores perdas, provavelmente em função da maior manipulação, aliada à resistência do ginóforo. A aplicação de calcário diminuiu significativamente as perdas, com exceção do tratamento em que as vagens foram levadas rapidamente para a estufa. Assim, pode-se inferir que o calcário melhorou a resistência dos ginóforos à deterioração. $\mathrm{O} \mathrm{Ca}$ em alta concentração inibe a atividade da poligalacturonase, responsável pela degradação da parede celular (PlattAloia et al., 1980), que, por sua vez, causa colapso do tecido afetado (Marschner, 1990). Embora os teores de Ca não tenham sido aumentados pela calagem, a relação $\mathrm{Ca} / \mathrm{Mn}$ foi diminuída.

$\mathrm{O}$ aumento das perdas em função do sistema de secagem deveu-se à movimentação das plantas e à degradação dos tecidos, que causaram a queda das ramificações $n+1$ (Tabela 4 ) e de vagens (Tabela 5) quando ficaram expostas a chuvas e alta umidade relativa. As perdas constatadas no tratamento sem calcário, em plantas que ficaram no campo até finalizar a secagem $(23 \%)$, foram superiores às observadas por Bragachini (1991), trabalhando com 
operações mecanizadas e com maior tempo de exposição no campo (105 dias), condições que favoreceriam a queda dos frutos.

A produtividade de vagens e grãos (Tabela 9) foi incrementada com a aplicação de calcário, dados que concordam com os de Quaggio et al. (1982), num solo com semelhantes valores de $\mathrm{Ca}\left(15,0 \mathrm{mmol}_{\mathrm{c}} \mathrm{dm}^{-3}\right)$, mas de menor $\mathrm{V}(40 \%)$ que o deste experimento (Tabela 1).

Pode-se considerar que o incremento da produção foi causado pela maior área foliar e matéria seca das folhas (55\% a mais) no início da frutificação (Tabela 2). Já Nakagawa \& Rosolem (1982) observaram uma correlação positiva entre matéria seca da parte aérea e produção de sementes. Outro fator que influenciou a produtividade foi a maior nodulação (Tabela 3), que se traduziu em maior acumulação de N. Tal resultado confirma os obtidos por

TABELA 6. Peso de sementes maduras, imaturas e da casca por planta no momento da colheita em função da calagem.

\begin{tabular}{cccc}
\hline Calagem & $\begin{array}{c}\text { Sementes } \\
\text { maduras }\end{array}$ & $\begin{array}{c}\text { Sementes } \\
\text { imaturas }\end{array}$ & Casca \\
\hline$\left(\mathrm{Mg} \mathrm{ha}^{-1)}\right.$ & - & - & $\left.-\mathrm{g} \mathrm{pl}^{-1}\right)$ \\
0 & 11,2 & 0,09 & 4,0 \\
2,05 & 17,9 & 0,13 & 6,1 \\
$\mathrm{~F}$ & $7,1^{\circ}$ & $1,22^{\mathrm{ns}}$ & $6,7^{\circ}$ \\
\hline $\mathrm{CV}(\%)$ & 48,8 & 82,1 & 45,1 \\
\hline${ }^{\circ}$ Teste F significativo a 10\% de probabilidade.
\end{tabular}

outros autores, que observaram aumento da produção com aumento do número e matéria seca dos nódulos (Alagawadi et al., 1983) e acumulação de $\mathrm{N}$ em pré-floração (Venkastewarlu et al., 1991). O incremento das ramificações secundárias aumentou o número de sítios de sustentação para os ginóforos (Tabela 4), traduzindo-se num maior número de vagens (Tabela 5). Esses dados concordam com Larshmaiah et al. (1983), que observaram incremento da produtividade com aumento do número de ramificações secundárias, e com Nakagawa \& Rosolem (1982), com aumento do número de ginóforos e frutos. Também houve maior porcentagem de vagens maduras e número de sementes por vagem (Tabela 6), principalmente as de três sementes, que representaram mais de $40 \%$ do total.

Por outro lado, a fitotoxicidade de Mn observada no início da frutificação pode ter sido responsável pelas menores produções obtidas na ausência de calagem.

Cabe ressaltar que a produtividade foi muito alta, ainda que os teores de $\mathrm{Ca}$ e $\mathrm{K}$ nas folhas estivessem abaixo daqueles considerados ótimos por Jones Junior et al. (1991). Assim, os teores de nutrientes obtidos neste trabalho podem ser considerados como adequados às altas produtividades.

O tipo de secagem modificou a produtividade de vagens e grãos (Tabela 9). As plantas que ficaram no campo por 11 e 13 dias tiveram o maior número de vagens com três sementes (Tabela 5) e maior perda de vagens (Tabela 8). Esses fatores foram os respon-

TABELA 7. Número de vagens chochas, podres, germinadas e com fungos, número de sementes germinadas e com fungos por planta, no momento da colheita em função do método de secagem¹.

\begin{tabular}{|c|c|c|c|c|c|c|}
\hline \multirow[t]{2}{*}{ Secagem $^{2}$} & \multicolumn{4}{|c|}{ Vagens } & \multicolumn{2}{|c|}{ Sementes } \\
\hline & Chochas & Podres & Germinadas & Com fungos & Germinadas & Com fungos \\
\hline Sombra & $0,04 \mathrm{a}$ & $0,12 \mathrm{ab}$ & $0,26 \mathrm{a}$ & $0,15 \mathrm{ab}$ & $0,12 \mathrm{a}$ & $0,28 \mathrm{a}$ \\
\hline Campo & $0,08 \mathrm{a}$ & $0,14 \mathrm{ab}$ & $0,31 \mathrm{a}$ & $0,26 \mathrm{a}$ & $0,50 \mathrm{a}$ & $0,64 a$ \\
\hline Estufa 1 & $0,00 \mathrm{a}$ & $0,06 \mathrm{~b}$ & $0,24 a$ & $0,20 \mathrm{ab}$ & $0,38 \mathrm{a}$ & $0,46 a$ \\
\hline Estufa 2 & $0,00 \mathrm{a}$ & $0,16 \mathrm{a}$ & $0,35 \mathrm{a}$ & $0,02 b$ & $0,38 \mathrm{a}$ & $0,10 \mathrm{a}$ \\
\hline Média & 0,03 & 0,12 & 0,29 & 0,16 & 0,34 & 0,37 \\
\hline $\mathrm{F}$ & $1,8^{\mathrm{ns}}$ & $3,0^{\circ}$ & $0,5^{\mathrm{ns}}$ & $3,8^{*}$ & $0,9^{\mathrm{ns}}$ & $2,6^{\circ}$ \\
\hline $\mathrm{CV}(\%)$ & 6,6 & 5,4 & 11,6 & 10,8 & 15,8 & 22,4 \\
\hline
\end{tabular}

1 Médias seguidas da mesma letra na coluna não diferem estatisticamente pelo teste de Tukey a $5 \%$ de probabilidade

2 Estufa 1: campo até $24,8 \%$ e depois estufa; Estufa 2: campo até $35,9 \%$ e depois estufa.

$\circ$, * Teste $\mathrm{F}$ significativo a 10 e $5 \%$ de probabilidade, respectivamente 
TABELA 8. Porcentagem de perdas após a secagem em função da calagem e do método de secagem ${ }^{1}$.

\begin{tabular}{|c|c|c|c|}
\hline Secagem $^{2}$ & Sem calcário & Com calcário & Média \\
\hline & \multicolumn{3}{|c|}{------------------------'(\%) -------------------- } \\
\hline Sombra & $3,2 \mathrm{cA}$ & $1,5 \mathrm{cB}$ & 2,3 \\
\hline Campo & $23,1 \mathrm{aA}$ & $10,9 \mathrm{aB}$ & 17,0 \\
\hline Estufa 1 & $7,7 \mathrm{bA}$ & $4,8 \mathrm{bB}$ & 6,3 \\
\hline Estufa 2 & $3,0 \mathrm{cA}$ & $2,7 \mathrm{bA}$ & 2,8 \\
\hline Média & 9,2 & 2,7 & \\
\hline \multicolumn{4}{|c|}{$\begin{array}{l}{ }^{1} \text { Médias seguidas da mesma letra maiúscula, nas linhas, e minúscula, nas } \\
\text { colunas, não diferem estatisticamente pelo teste de Tukey a } 5 \% \text { de pro- } \\
\text { babilidade. } \\
2 \text { Estufa 1: campo até } 24,8 \% \text { e depois estufa; Estufa 2: campo até } 35,9 \% \text { e } \\
\text { depois estufa. }\end{array}$} \\
\hline
\end{tabular}

TABELA 9. Produtividade de vagens e grãos e rendimento (peso de grãos/peso de vagens) de amendoim em função da calagem e do método de secagem 1 .

\begin{tabular}{|c|c|c|c|}
\hline \multirow[t]{2}{*}{ Calagem } & \multicolumn{2}{|c|}{ Produtividade } & \multirow[t]{2}{*}{ Rendimento } \\
\hline & Vagens & Grãos & \\
\hline$\left(\mathrm{Mg} \mathrm{ha}^{-1}\right)$ & \multicolumn{2}{|c|}{ - $\left(\mathrm{kg} \mathrm{ha}^{-1}\right)$} & $(\%)$ \\
\hline 0 & 4753,0 & 3525,0 & 74,2 \\
\hline 2,05 & 7142,2 & 5353,3 & 74,9 \\
\hline $\mathrm{F}$ & $49,1^{* *}$ & $49,6^{* * *}$ & $8,6^{\circ}$ \\
\hline $\mathrm{CV}(\%)$ & 16,2 & 16,4 & 1,0 \\
\hline \multicolumn{4}{|l|}{ Secagem $^{2}$} \\
\hline Sombra & $6372,3 \mathrm{ab}$ & $4737,7 \mathrm{ab}$ & $74,4 \mathrm{a}$ \\
\hline Campo & $5123,3 \mathrm{c}$ & $3841,6 \mathrm{c}$ & $75,0 \mathrm{a}$ \\
\hline Estufa 1 & $5736,8 \mathrm{bc}$ & $4309,3 b c$ & $75,1 \mathrm{a}$ \\
\hline Estufa 2 & $6557,9 \mathrm{a}$ & $4888,1 \mathrm{a}$ & $74,5 \mathrm{a}$ \\
\hline Média & 5947,6 & 4441,3 & 74,7 \\
\hline $\mathrm{F}$ & $16,7^{* *}$ & $16,0^{* *}$ & $1,1^{\mathrm{ns}}$ \\
\hline CV (\%) & 7.6 & 7.5 & 1.3 \\
\hline
\end{tabular}

${ }^{1}$ Médias seguidas da mesma letra na coluna não diferem estatisticamente pelo teste de Tukey a $5 \%$ de probabilidade.

2 Estufa 1: campo até $24,8 \%$ e depois estufa; Estufa 2: campo até 35,9\% e depois estufa

$\circ$, **Teste $\mathrm{F}$ significativo a 10 e $1 \%$ de probabilidade, respectivamente

sáveis pela diminuição da produção quando as plantas ficaram no campo por um tempo prolongado, sujeitas à movimentação e a fatores ambientais adversos. Embora as perdas tenham sido diminuídas pela aplicação de calcário (Tabela 8), não houve reflexo na produtividade.
O rendimento no beneficiamento (Tabela 9) não foi modificado pelo calcário, concordando com Caires (1990), nem pelo sistema de secagem.

\section{CONCLUSÕES}

1. A calagem elimina a fitotoxicidade de man-ganês, melhorando a nodulação e a nutrição nitrogenada da planta.

2. A melhor nutrição proporcionada pela calagem resulta em maior número de ramificações, maior número de vagens por planta e, conseqüentemente, maior produtividade.

3. A calagem previne a deterioração dos ginóforos, o que resulta em menores perdas na colheita.

4. As secagens à sombra e combinada campo-estufa proporcionam maior produtividade por permitirem melhor maturação dos frutos e menores perdas na colheita.

\section{REFERÊNCIAS}

ADAMS, J.F.; HARTZOG, D.L. Seed quality of runner peanuts as affected by gypsum and soil calcium. Journal of Plant Nutrition, New York, v.14, n.8, p.841-851, 1991

ADAMS, J.F.; PEARSON, R.W. Differential response of cotton and peanuts to subsoil acidity. Agronomy Journal, Madison, v.62, p.9-14, 1970.

ALAGAWADI, A.R.; SIDDARAMEGOWDA, T.K.; HABIB, A.F. Groundnut crop response to Rhizobium inoculation. Madras Agricultural Journal, Coimbatore, v.70, n.10, p.635-637, 1983.

BEKKER, A.W.; HUE, N.U.; YAPA, L.G.G.; CHASE, R.G. Peanut growth as affected by liming, Ca-Mn interactions, and $\mathrm{Cu}$ plus $\mathrm{Zn}$ applications to oxidic Samoan soils. Plant and Soil, Dordrecht, v.164, p.203-211, 1994

BLAMEY, F.P.C.; CHAPMAN, J. Soil amelioration effects on peanut growth, yield and quality. Plant and Soil, Dordrecht, v.65, p.319-334, 1982.

BOOTE, K.J. Growth stages of peanut (Arachis hypogaea L.). Peanut Science, Yoakum, v.9, p.35-40, 1982.

BRADY, N.C. The effect of period of calcium supply and mobility of calcium in the plant on peanut fruit filling. Soil Science Society of America. Proceedings, Madison, v.11, p.336-341, 1947. 
BRAGACHINI, M.A.; BONETTO, L.A.; CASINI, C.; RITTATORE, M.J.; ZARATE, C.G.; HERBENER, N.; CARRIZO, R.; MACARRONE, H.; BONGIOVANNI, R.; OCHETI, E.; CASTELANO, $\mathrm{S}$. Cosecha de mani. Buenos Aires: PROPECO/ INTA, 1991. p.1-13. (Informativo Técnico, 2).

BURKHART, L.; COLLINS, E.R. Mineral nutrients in peanuts plant growth. Soil Science Society of America. Proceedings, Madison, v.6, p.272-280, 1941.

BURSTRÖM, H.G. Calcium and plant growth. Biological Review of the Cambridge Philosophical Society, Cambridge, v.43, p.287-316, 1968.

CAIRES, E.F. Resposta diferencial de genótipos de amendoim (Arachis hypogaea L.) à calagem. Botucatu: UNESP, Faculdade de Ciências Agronômicas, 1990. 114p. Dissertação de Mestrado.

CAIRES, E.F.; ROSOLEM, C.A. Root growth of peanut cultivars and soil acidity. In: WRIGHT, R.J.; BALIGAR, V.C.; MURRMANN, P. (Eds.). Plant-soil interactions at low pH. Dordrecht: Kluwer Academic Publ., 1991. p.234-243.

COLWELL, W.E.; BRADY, N.C. The effects of calcium on yield and quality of large-seed type peanuts. Journal of the American Society of Agronomy, Madison, v.37, n.413-428, 1945.

COX, F.R.; REID, P.H. Calcium-boron nutrition as related to canceled damage in peanuts. Agronomy Journal, Madison, v.56, p.173-176, 1964.

HALLOCK, D.L; ALLISON, A.N. Effect of three Ca source applied on peanuts. 1. Productivity and seed quality. Peanut Science, Yoakum, v.7, n.1, p.19$-25,1980$.

HEENAN, D.P.; CARTER, O.G. Influence of temperature on expression of manganese toxicity by two soybean varieties. Plant and Soil, Dordrecht, v.47, p.219$-227,1977$

INOUE, K.; YOKATA, H.; YAMADA, Y. Effect of Ca in the medium on root growth under low $\mathrm{pH}$ conditions. Soil Science and Plant Nutrition, Tokyo, v.34, n.3, p.359-374, 1988.

JONES JUNIOR, J.B.; WOLF, B.; MILLS, H.A. Plant analysis handbook. Athens, GA: Micro-Macro Publ., 1991. 213p.

KVIEN, C.S.; BRANCH, W.D.; SUMNER, M.E.; CSINOS, A.S. Pod characteristics influencing calcium concentrations in the seed and hull of peanut. Crop Science, Madison, v.28, p.666-671, 1988.
LARSHMAIAH, B.; REDDY, P.S.; REDDY, B.M. Selection criteria for improving yield in groundnut (Arachis hypogaea L.). Oleagineux, Paris, v.38, n.11, p.607-613, 1983.

MARSCHNER, H. Mineral nutrition of higher plants. San Diego: Academic Press, 1990. 674p.

MASCARENHAS, J.P.; MACHKIS, L. Chemotropic response of the pollen of Antirrhinum majus to calcium. Plant Physiology, Bethesda, v.39, p.70$-77,1964$.

MIZUNO, S. Physiological studies on the fructification of peanut. 1. Distribution of radioactive calcium administered to the fruiting zone in the fruiting organ. Proceedings of the Science Society of Japan, Tokio, v.28, p.83-85, 1959

MORRIS, H.D.; PIERRE, W.H. Minimum concentration of manganese necessary for injury to various legumes in culture solutions. Agronomy Journal, Madison, v.5, p.107-112, 1949.

NAKAGAWA, J.; NAKAGAWA, J.; IMAIZUMI, I.; ROSSETTO, C.A.V. Efeitos de fontes de fósforo e da calagem na produção de amendoim. Pesquisa Agropecuária Brasileira, Brasília, v.28, n.4, p.421-431 , abr. 1993.

NAKAGAWA, J.; ROSOLEM, C.A. Correlação entre algumas características da planta da cultivar "Tatu" de amendoim (Arachis hypogaea L.). Ecossistema, Espírito Santo do Pinhal, v.7, p.5-7, 1982

NORDEN, A.J. Effect of curing method on peanut seed quality. Peanut Science, Yoakum, v.2, n.1, p.33$-37,1975$.

PLATT-ALOIA, K.A.; THOMSON, W.W.; YOUNG, R.E. Ultrastructural changes in the walls of ripening avocados: transmission, scanning and freeze fracture microscopy. Botanical Gazette, v.141, p.366-373, 1980.

QUAGGIO, J.A.; DECHEN, A.R.; RAIJ, B. van. Efeitos da aplicação de calcário e gesso sobre a produção de amendoim e lixiviação de bases do solo. Revista Brasileira de Ciência do Solo, Campinas, v.6, p.189194, 1982.

RAIJ, B. van. Avaliação da fertilidade do solo. Piracicaba: POTAFOS, 1981. 142p.

REDDY, S.C.S.; PATI, S.V. Effect of calcium and sulphur and certain minor nutrient elements on the growth yield and quality of groundnut (Arachis hypogaea L.). Oleagineux, Paris, v.35, n.11, p.507--510, 1980. 
REED, J.F.; BRADY, N.C. Time and method of supplying calcium as affecting production of peanuts. Journal of the American Society of Agronomy, Madison, v.40, p.980-996, 1948.

RODRIGUES FILHO, F.S.O.; FEITOSA, C.T.; GERIN, M.A.N. Omissão de macronutrientes em plantas de amendoim. Bragantia, Campinas, v.47, p.305-312, 1988.

ROSSETTO, C.A.V. Efeitos da colheita e da calagem na produção e qualidade de sementes de amendoim (Arachis hypogaea L.) cv. Botutatu. Botucatu: UNESP, Faculdade de Ciências Agronômicas, 1993. 114p. Dissertação de Mestrado.

SUMNER, M.E.; KVIEN, C.S.; SMALL, H.; CSINOS, A.S. On the Ca nutrition of peanut (Arachis hypogaea L.). I. Conceptual model. Journal of Fertilizer Issues, Manchester, MO, v.5, n.3, p.97$-102,1988$
VENKASTEWARLU, B.; MAHESWARI, M.; REDDY, G.S. Relationship between nodulation, nitrogen fixation rate, $\mathrm{N}$-harvest index and kernel yield in different groundnut varieties under dryland conditions. Oleagineux, Paris, v.46, n.6, p.239-246, 1991.

WALKER, M.E. Calcium requirements for peanuts. Communications in Soil Science and Plant Analysis, New York, v.6, n.3, p.299-313, 1975.

WRIGHT, F.S.; STEELE, J.L. Potential for direct harvesting of peanuts. Peanut Science, Yoakum, v.6, p.37-42, 1979.

YOUNG, J.H.; PEARSON, N.K.; DONALD, J.O.; MAFIELD, W.D. Harvesting, curing and energy utilization. In: PATTE, H.E.; YOUNG, C.T. (Eds.). Peanut: science and technology. Yoakum: APRES, 1982. ch. 12 , p.458-485. 